\title{
Decrease in Ambient Fine Particulate Matter during COVID-19 Crisis and Corresponding Health Benefits in Seoul, Korea
}

\author{
Changwoo Han ${ }^{1}$ and Yun-Chul Hong ${ }^{2,3,4, *}$ \\ 1 Department of Preventive Medicine, Chungnam National University College of Medicine, \\ Daejeon 35015, Korea; cwohan@cnu.ac.kr \\ 2 Department of Preventive Medicine, Seoul National University College of Medicine, Seoul 03080, Korea \\ 3 Institute of Environmental Medicine, Seoul National University Medical Research Center, Seoul 03080, Korea \\ 4 Environmental Health Center, Seoul National University College of Medicine, Seoul 03080, Korea \\ * Correspondence: ychong1@snu.ac.kr; Tel.: +82-2-740-8394
}

Received: 6 July 2020; Accepted: 21 July 2020; Published: 22 July 2020

\begin{abstract}
Both domestic emissions and transported pollutants from neighboring countries affect the ambient fine particulate matter $\left(\mathrm{PM}_{2.5}\right)$ concentration of Seoul, Korea. Diverse measures to control the coronavirus disease 2019 (COVID-19), such as social distancing and increased telecommuting in Korea and the stringent lockdown measures of China, may reduce domestic emissions and levels of transported pollutants, respectively. In addition, wearing a particulate-filtering respirator may have decreased the absolute $\mathrm{PM}_{2.5}$ exposure level for individuals. Therefore, this study estimated the acute health benefits of $\mathrm{PM}_{2.5}$ reduction and changes in public behavior during the COVID-19 crisis in Seoul, Korea. To calculate the mortality burden attributable to $\mathrm{PM}_{2.5}$, we obtained residents' registration data, mortality data, and air pollution monitoring data for Seoul from publicly available databases. Relative risks were derived from previous time-series studies. We used the attributable fraction to estimate the number of excessive deaths attributable to acute $\mathrm{PM}_{2.5}$ exposure during January to April, yearly, from 2016 to 2020, and the number of mortalities avoided from $\mathrm{PM}_{2.5}$ reduction and respirator use observed in 2020. The average $\mathrm{PM}_{2.5}$ concentration from January to April in $2020\left(25.6 \mu \mathrm{g} / \mathrm{m}^{3}\right)$ was the lowest in the last 5 years. At least $-4.1 \mu \mathrm{g} / \mathrm{m}^{3}(95 \% \mathrm{CI}:-7.2,-0.9)$ change in ambient $\mathrm{PM}_{2.5}$ in Seoul was observed in 2020 compared to the previous 4 years. Overall, 37.6 (95\% CI: 32.6, 42.5) non-accidental; 7.0 (95\% CI: 5.7, 8.4) cardiovascular; and 4.7 (95\% CI: 3.4, 6.1) respiratory mortalities were avoided due to $\mathrm{PM}_{2.5}$ reduction in 2020. By considering the effects of particulate respirator, decreases of 102.5 (95\% CI: 89.0, 115.9) non-accidental; 19.1 (95\% CI: 15.6, 22.9) cardiovascular; and 12.9 (95\% CI: 9.2, 16.5) respiratory mortalities were estimated. We estimated that 37 lives were saved due to the $\mathrm{PM}_{2.5}$ reduction related to COVID-19 in Seoul, Korea. The health benefit may be greater due to the popular use of particulate-filtering respirators during the COVID-19 crisis. Future studies with daily mortality data are needed to verify our study estimates.
\end{abstract}

Keywords: COVID-19; particulate matter; lockdown; health burden; mortality; Korea

\section{Introduction}

The world is facing one of its gravest challenges due to the coronavirus disease 2019 (COVID-19). After the first unknown pneumonia cases detected in Wuhan, China, in December 2019, scientists identified new species of the zoonotic coronavirus, severe acute respiratory syndrome coronavirus 2 (SARS-COV-2), causing COVID-19 [1,2]. COVID-19 may lead to a fatal respiratory disease in the elderly and in persons with preexisting chronic diseases, but the symptoms can be mild in young and healthy individuals [3]. According to the report from the Chinese Center for Disease Control using the 44,672 
confirmed COVID-19 cases, the case fatality rate was 2.3\%, lower compared to other coronaviruses causing severe acute respiratory syndrome (SARS, 9.6\%) and Middle East respiratory syndrome (MERS, $35.5 \%)[4,5]$. However, SARS-COV-2 is highly infectious, with an estimated reproduction number $\left(R_{0}\right)$ over 3, causing more mortalities than any other coronaviruses [5-7]. Due to the wide geographical spread of the virus and the growing international concern, the World Health Organization (WHO) declared COVID-19 outbreak as a pandemic on 12 April 2020. As of 24 April 2020, COVID-19 has killed more than 190,800 people, with 4.6 million confirmed cases worldwide. Billions of people were instructed or forced to stay at home while countries locked their borders to varying degrees to control COVID-19.

After the first incidence of COVID-19 on 20 January 2020, Korea has controlled the outbreak relatively well compared to other countries. Although there was a surge of COVID-19 in Daegu City, which peaked at over 900 incident cases on 29 February, the daily increase in new cases in Korea had dropped below 10 by the end of April [8]. Without imposing extreme measures to restrict the movement or freedom of the citizens, Korea was able to flatten the curve of the new cases. This was achieved by a massive number of tests conducted for early detection, by applying rigorous epidemiological investigation, and sharing information using the state of the art information and communication technologies [8,9]. These all occurred with the voluntary participation of social distancing and personal hygiene practices (i.e., wearing respirators in public space and washing hands) by the citizens. To address the shortage and ensure the equal distribution of respirators, the Korean government adopted a "5-day rotation system for a respirator" to provide opportunities for people to purchase a respirator at pharmacies on designated days according to their birth years.

Recently, the diverse news media, journal papers, and reports posted on the preprint server medRxic have indicated that the stringent lockdown measures not only helped in controlling the spread of this highly infectious virus, but also helped to decrease the ambient air pollution levels, including particulate matter less than $2.5 \mu \mathrm{m}$ in diameter $\left(\mathrm{PM}_{2.5}\right)$ and nitrogen dioxide $\left(\mathrm{NO}_{2}\right)[10,11]$. With the lockdown of industrial activities and transportation in China for about 35 days, there was a 30.1 and $9.2 \mu \mathrm{g} / \mathrm{m}^{3}$ decrease in $\mathrm{PM}_{2.5}$ in Wuhan and Beijing, respectively [12]. One report estimated a 12.9 and $18.9 \mu \mathrm{g} / \mathrm{m}^{3}$ decrease in $\mathrm{NO}_{2}$ and $\mathrm{PM}_{2.5}$ in China after the massive population quarantine [13]. Satellites of National Aeronautics and Space Administration (NASA) and European Space Agency detected a 10 to $20 \%$ decrease in $\mathrm{NO}_{2}$ levels over eastern and central China after the quarantine [14]. The Movement Control Order of the Malaysian government to encourage their citizens to work at home and suspend industrial activities caused a decrease in $\mathrm{PM}_{2.5}$ levels [15]. Lockdown measures such as school closure, work at home, avoiding gatherings, shutting down commerce, and limiting public transportation in the city of Rio de Janeiro and São Paulo State caused a reduction in carbon monoxide and $\mathrm{NO}_{2}$ levels [16,17]. Another report estimated a 9\%, 29\%, and $11 \%$ global reduction in ambient $\mathrm{PM}_{2.5}, \mathrm{NO}_{2}$, and ozone levels, respectively, after the COVID-19 crisis [18].

A recent announcement by Korea's Ministry of Environment revealed a reduction in the average $\mathrm{PM}_{2.5}$ in Korea from December 2019 to April 2020 by $27 \%\left(9 \mu \mathrm{g} / \mathrm{m}^{3}\right)$ compared to that of the previous year [19]. Although the report highlighted the effectiveness of "the seasonal particle pollution measures", which was newly implemented in December 2019, the marked PM $_{2.5}$ decrease observed in China as well as around the world suggest that the measures to control COVID-19 may be the largest contributing factor behind the improved air quality. In addition, a recent modeling study showed that around $70 \%$ of $\mathrm{PM}_{2.5}$ concentration of Seoul is affected by the emission from China during the days with severe $\mathrm{PM}_{2.5}$ concentration in spring [20].

Therefore, we initiated this study with a reasonable assumption that social distancing and increased telecommuting in Korea, in addition to the stringent lockdown measures and reduced industrial activities in China, may have reduced the $\mathrm{PM}_{2.5}$ levels in Seoul, the capital city of Korea. Furthermore, the respirators supplied and distributed by the Korean government were effective in filtering $\mathrm{PM}_{2.5}$ at least $80 \%$ of the $0.6 \mu \mathrm{m}$ nonoil particulates. Therefore, each person would be exposed to a lower level of $\mathrm{PM}_{2.5}$ compared to the period before the COVID-19 crisis by using the particulate 
filtering respirator. Based on this assumption, we estimated the acute health benefits of $\mathrm{PM}_{2.5}$ reduction and changes in public behavior (wearing of a respirator) during the COVID-19 crisis using the health impact assessment methodology. The aim of this study was to use currently available data to estimate the acute health benefits of $\mathrm{PM}_{2.5}$ reduction and changes in public behavior, which were changes experienced by Korean citizens in their daily lives during the COVID-19 crisis.

\section{Materials and Methods}

\subsection{Study Design}

The health impact assessment requires data on exposure, mortality, and the population. Although Korea shares the real-time air pollution monitoring data with the public, the mortality data are not shared simultaneously. Therefore, we estimated the mortality rates over the last 2 years (2019 and 2020) based on the mortality rates of earlier years. With the $\mathrm{PM}_{2.5}$ monitoring data, population data, and estimated mortality rates in Seoul, we estimated the health benefits based on the $\mathrm{PM}_{2.5}$ reduction levels in 2020. By using previous respirator intervention study results [21], we estimated the health benefits of decreased $\mathrm{PM}_{2.5}$ and respirator use in 2020.

To estimate the $\mathrm{PM}_{2.5}$ decrease in year 2020, we first calculated the average $\mathrm{PM}_{2.5}$ concentration during the first 4 months of 2020 and compared it with the concentration in the same months, each year, from 2016 to 2019. By using the attributable fraction (AF) method [22], we estimated the mortality burden attributable to the acute ambient $\mathrm{PM}_{2.5}$ exposure in the first 4 months of each year, and the number of mortalities avoided due to the observed $\mathrm{PM}_{2.5}$ reduction in 2020.

To calculate the mortality burden attributable to $\mathrm{PM}_{2.5}$, we obtained the population, mortality, and air pollution monitoring data of Seoul from publicly available databases. The relative risks (RR) derived from previous time-series studies, which evaluated the association between ambient $\mathrm{PM}_{2.5}$ exposure and cause-specific mortalities were reviewed to retrieve the beta estimates of the concentration-response functions $[23,24]$. To consider the effects of public respirator use, we referred to previous intervention study, which evaluated the difference between individual $\mathrm{PM}_{2.5}$ exposure level by the particulate respirator use [21].

Several important assumptions were made for our study. Because mortality data were unavailable for the last two years (2019 and 2020), we assumed that mortality rates in Seoul from January to April had not changed in the last 5 years. In Korea, the daily mortality data for a typical year become publicly available at least 1.5 years after the year ends. Therefore, we estimated the mortality rates of Seoul from January to April in 2019 and 2020 by averaging the mortality rates of the same months from 2016 to 2018. Because the mortality rates are closely related to the structure of the population, we also assumed that the composition of the population by age groups had not changed during our study period.

Second, we assumed that the effects of $\mathrm{PM}_{2.5}$ were limited to a single day, ignoring the delayed effect of $\mathrm{PM}_{2.5} \cdot \mathrm{PM}_{2.5}$ is known to have lag effects of several days after the exposure [25]. However, because the daily mortality counts were unavailable for the years 2019 and 2020, it was impossible to estimate the daily levels accounting for lag effects of $\mathrm{PM}_{2.5}$. Therefore, we regarded the 4-month period as a whole and calculated the mortality burden for each year using the 4-month averages of $\mathrm{PM}_{2.5}$ concentrations and the estimated mortality rates of Seoul. Assumption focusing on a single day effect of $\mathrm{PM}_{2.5}$ may underestimate the overall mortality burden attributable to $\mathrm{PM}_{2.5}$. However, the avoided number of mortalities due to $\mathrm{PM}_{2.5}$ reduction during the COVID-19 crisis may not be biased because we focused on the changes in $\mathrm{PM}_{2.5}$ levels with the assumption of a linear concentration-response function.

Third, we assumed that the effects of $\mathrm{PM}_{2.5}$ concentration on health outcomes did not change during the study period, despite the changes in personal behaviors (i.e., social distancing and decreased outdoor activities) due to the COVID-19 crisis. We adopted the RRs from the previous time-series studies conducted both in Seoul and that in 652 cities around the globe [23,24]. However, despite assuming that the slope of concentration-response function between $\mathrm{PM}_{2.5}$ and mortality remained unchanged, 
we assumed that wearing a particulate filtering respirator would decrease the absolute level of $\mathrm{PM}_{2.5}$ exposure of an individual.

This study was exempt from review by the Institutional Review Board of the Seoul National University Hospital, Korea (IRB No.: 2006-122-1133), because data used in our study were de-identified and publicly available.

\subsection{Population and Mortality Data}

The yearly residents' registration data for January during the study period (2016 to 2020) and the cause-specific mortality data for January to April (2016 to 2018) were acquired from the publicly available databases, the Korean Statistical Information Service website, and the Korean Statistical Information Service MicroData Integrated Service website [26,27].

We used the International Classification of Disease, 10th revision codes to define the following cause-specific mortalities: non-accidental and specific disease mortality (A00-R00), cardiovascular disease mortality (I00-199), and respiratory disease mortality (J00-J99). The number of deaths due to these disease categories during the 4 months (January to April) of each year was calculated and divided by the number of registered residents in January of the corresponding year, to calculate the 4-month average in mortality rates of Seoul.

\section{3. $\mathrm{PM}_{2.5}$ and Meteorological Data}

Ambient $\mathrm{PM}_{2.5}$ data of Seoul from January 2016 to April 2020 were accessed through the Airkorea website, which provides real-time air pollution monitoring data of Korea [28]. Korea operates 25 air pollution monitoring stations in Seoul, covering 25 basic administration districts. We acquired the hourly $\mathrm{PM}_{2.5}$ monitoring results from each station, and calculated Seoul's daily and 4-month average of $\mathrm{PM}_{2.5}$ exposure levels for January to April each year from 2016 to 2020. Daily meteorological data such as ambient temperature, relative humidity, and wind speed from January 2016 to April 2020 were accessed through the National Climate Data Center website. The map of Seoul and the locations of the ambient $\mathrm{PM}_{2.5}$ as well as the weather monitoring stations are presented in Figure S1.

\subsection{Concentration-Response Functions and Effects of Particulate Matter Filtrating Respirator}

The beta estimates of the concentration-response functions were retrieved from the RRs of the previous time-series studies that evaluated the association between ambient $\mathrm{PM}_{2.5}$ exposure and cause-specific mortalities (Supplementary Table S1). We selected two recently published studies—one analyzing the data from cities around the globe, and the other limited to Seoul. In brief, the Multi-City Multi-Country (MCC) collaborative research network gathered the daily mortality rates and $\mathrm{PM}_{2.5}$ data from 499 cities in 16 countries. The researchers found that a $10 \mu \mathrm{g} / \mathrm{m}^{3}$ increase in a 2-day moving average of ambient $\mathrm{PM}_{2.5}$ was associated with $0.68 \%$ (95\% confidence interval (CI): 0.59, 0.77); $0.55 \%$ (95\% CI: 0.45, 0.66); and 0.75\% (95\% CI: 0.53, 0.95) increase in the daily non-accidental, cardiovascular, and respiratory mortalities, respectively [23].

The study conducted in Seoul used the daily $\mathrm{PM}_{2.5}$ concentrations and mortality data of the city from 2006 to 2012. A $10 \mu \mathrm{g} / \mathrm{m}^{3}$ increase in ambient $\mathrm{PM}_{2.5}$ was associated with an increase in non-accidental mortality $(0.33 \%(95 \%$ CI: $0.01,0.66))$, cardiovascular mortality $(0.76 \%$ (95\% CI: 0.12 , $1.41))$, and respiratory mortality $(1.77 \%(95 \%$ CI: $0.55,3.01))$ on the same day in Seoul [24].

In a previous intervention study with 21 female elderlies in Korea, we evaluated the effects of a particulate-filtering respirator on cardiopulmonary function by using the crossover study design [21]. The subjects were instructed to use (intervention period) or not use the respirator (control period) for six consecutive days and had a medical examination on the last day of each period. By using the disposable particulate respirators (capable of filtering $80 \%$ of the $0.6 \mu \mathrm{m}$ nonoil particulates), we found that the average level of personal exposure to $\mathrm{PM}_{2.5}$ had decreased by $27.4 \%\left(9.0 \mu \mathrm{g} / \mathrm{m}^{3}\right.$ reduction) during the respirator use, and even the outdoor $\left(27.4-28.8 \mu \mathrm{g} / \mathrm{m}^{3}\right)$ and 24-h personally monitored $\mathrm{PM}_{2.5}$ levels $\left(18.7-20.1 \mu \mathrm{g} / \mathrm{m}^{3}\right)$ were similar between intervention and control periods. By referring 
to this value, we estimated that the effects of respirator use during COVID-19 crisis decreased the personal $\mathrm{PM}_{2.5}$ exposure level by $27.4 \%$ in addition to the decrease in ambient $\mathrm{PM}_{2.5}$ levels observed during 2020.

\subsection{Statistical Analysis}

With the estimated number of mortalities and monitored $\mathrm{PM}_{2.5}$ concentrations from January to April each year, we used the AF method to estimate the mortality burden attributable to ambient $\mathrm{PM}_{2.5}$ levels [22].

$$
\text { Excess deaths by } P M_{2.5}=\left(1-\exp ^{-\beta \times \Delta C}\right) \times \text { Number of deaths }
$$

$\beta$ is the coefficient derived from the RRs in the previous time-series studies and $\Delta C$ refers to the changes in the $\mathrm{PM}_{2.5}$ concentrations under different counterfactual scenarios. The number of deaths from January to April for the years 2016 to 2018 was obtained from the mortality database, while those of 2019 and 2020 were calculated by multiplying the number of registered residents with the mortality rates estimated based on the mortality rates of 2016 to 2018.

To calculate the number of excess deaths attributable to the acute $\mathrm{PM}_{2.5}$ exposure from January to April each year from 2016 to 2020 , we defined $2.4 \mu \mathrm{g} / \mathrm{m}^{3}$ as the concentration with the minimum health risk, which is the theoretical minimum risk exposure level, indicating no health benefits for reducing $\mathrm{PM}_{2.5}$ below the level based on prior epidemiological studies [29]. Therefore, $\Delta C$ in the equation indicates the difference between average $\mathrm{PM}_{2.5}$ concentrations monitored each year from January to April and $2.4 \mu \mathrm{g} / \mathrm{m}^{3}$. On the other hand, to calculate the avoided mortality due to $\mathrm{PM}_{2.5}$ reduction in 2020, we defined $\Delta C$ as the estimated reduction in $\mathrm{PM}_{2.5}$ from January to April in 2020 compared to the same months in 2016-2019.

To calculate the reduction in $\mathrm{PM}_{2.5}$ in 2020, we used the linear regression models assuming the normal distribution of $\mathrm{PM}_{2.5}$ levels. In model 1, the amount of reduction was estimated based on a simple comparison of the average value for 2020 with the average for the years 2016-2019. In model 2, we adjusted for meteorological variables (daily average temperature, relative humidity, and wind speed), and in model 3, we adjusted for the meteorological variables, years (as a continuous variable), and the months (as a categorical variable). In model 4, we adjusted for the meteorological variables and assumed that the average level of personal exposure to $\mathrm{PM}_{2.5}$ had decreased by $27.4 \%$ in 2020 , to account for the widespread use of particulate filtrating respirator.

All analyses were conducted with SAS version 9.4 (SAS Institute Inc., Cary, NC, USA), and figures were drawn using the R statistical software (Version 3.6.1; R Foundation for Statistical Computing, Vienna, Austria). The level of statistical significance was set at a $p$-value of less than 0.05 .

\section{Results}

Table 1 and Figure 1 show the 2016 to 2020 Seoul data for the daily $\mathrm{PM}_{2.5}$ concentrations, ambient temperature, relative humidity, wind speed, and the number of days that the $\mathrm{PM}_{2.5}$ concentration was above the WHO and Korea 24-h average standards. The average ambient temperature from January to April in 2020 was the highest compared to those of the previous 4 years, while the relative humidity and wind speed of 2020 were similar to that of 2016 and 2017.

The average $\mathrm{PM}_{2.5}$ concentration from January to April in $2020\left(25.6 \mu \mathrm{g} / \mathrm{m}^{3}\right)$ was the lowest in the last 5 years. Overall, the $\mathrm{PM}_{2.5}$ concentrations above the WHO $\left(25 \mu \mathrm{g} / \mathrm{m}^{3}\right)$ and the Korean standards $\left(35 \mu \mathrm{g} / \mathrm{m}^{3}\right)$ in 2020 were for 55 days $(45.5 \%)$ and 25 days $(20.7 \%)$ respectively, which were the least number of days in the past 5 years. Figure 1 shows the dramatic decrease in the daily $\mathrm{PM}_{2.5}$ concentrations as well as the number of days with spiking $\mathrm{PM}_{2.5}$ concentrations in 2020 compared to the previous 4 years.

Table 2 shows the number of registered residents, estimated number of deaths, and mortality rates used in the study. The average number of registered residents in Seoul in January each year was $9,860,115$. The average non-accidental, cardiovascular, and respiratory mortalities per 100,000 persons in Seoul were 139.2, 32.0, and 16.1 from January to April in 2016 to 2018, respectively. We used these 
mortality rates to estimate the number of deaths for 2019 and 2020 assuming that these rates remained unchanged. We estimated that 13,549; 3115; and 1567 persons died in Seoul from January to April in 2020 due to non-accidental, cardiovascular, and respiratory diseases, respectively.

Table 1. Average daily particulate matter $\left(\mathrm{PM}_{2.5}\right)$ concentrations, temperature, relative humidity, wind speed, and number of days over the WHO $\left(25 \mu \mathrm{g} / \mathrm{m}^{3}\right)$ and Republic of Korea $\left(\mathrm{ROK}, 35 \mu \mathrm{g} / \mathrm{m}^{3}\right) \mathrm{PM}_{2.5}$ 24-h average standards in Seoul (January to April each year from 2016 to 2020).

\begin{tabular}{cccccccc}
\hline Year & Days (N) & $\begin{array}{c}\mathbf{P M}_{\mathbf{2 . 5}} \\
\left(\mu \mathrm{g} / \mathbf{m}^{\mathbf{3}}\right)^{(\mathbf{a})}\end{array}$ & $\begin{array}{c}\text { Temperature } \\
\left({ }^{\circ} \mathbf{C}\right)\end{array}$ & $\begin{array}{c}\text { Relative } \\
\text { Humidity } \\
\mathbf{( \% )}^{(\mathbf{a})}\end{array}$ & $\begin{array}{c}\text { Wind Speed } \\
(\mathbf{m} / \mathbf{s})\end{array}$ & $\begin{array}{c}\text { Days over } \\
\text { WHO } \\
\text { Standard }\end{array}$ & $\begin{array}{c}\text { Days over } \\
\mathbf{\text { ROK }} \\
\text { Standard }^{(\mathbf{b})}\end{array}$ \\
\hline 2016 & 121 & $28.1(11.1)$ & $4.5(7.8)$ & $52.7(14.4)$ & $2.5(0.7)$ & $64(52.9)$ & $33(27.3)$ \\
2017 & 120 & $31.7(15.2)$ & $4.6(7.1)$ & $52.1(12.7)$ & $2.4(0.7)$ & $71(59.2)$ & $40(33.3)$ \\
2018 & 120 & $30.6(18.3)$ & $3.9(8.4)$ & $51.8(14.4)$ & $2.0(0.7)$ & $64(53.3)$ & $40(33.3)$ \\
2019 & 120 & $34.6(23.6)$ & $4.9(6.0)$ & $48.8(14.6)$ & $1.9(0.6)$ & $63(52.5)$ & $39(32.5)$ \\
2020 & 121 & $25.6(12.2)$ & $5.8(5.3)$ & $52.4(13.5)$ & $2.5(0.8)$ & $55(45.5)$ & $25(20.7)$ \\
\hline
\end{tabular}

(a) Mean and standard deviation are presented, ${ }^{(b)}$ Number of days and percentage are presented.

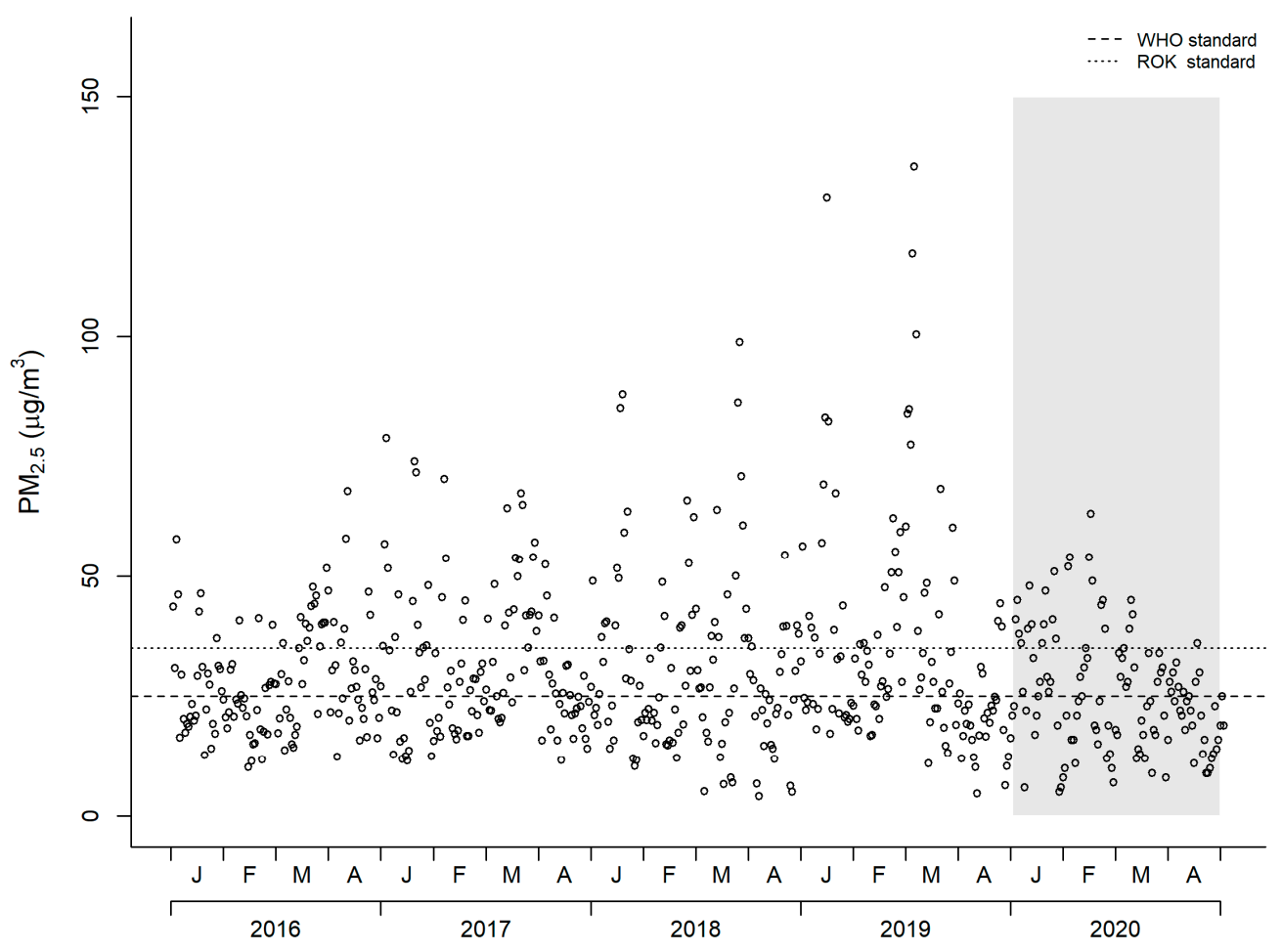

Figure 1. $\mathrm{PM}_{2.5}$ concentration in Seoul from year 2016 to 2020 (January to April).

Table 2. Number of registered population, number of deaths, and mortality rates used in this study.

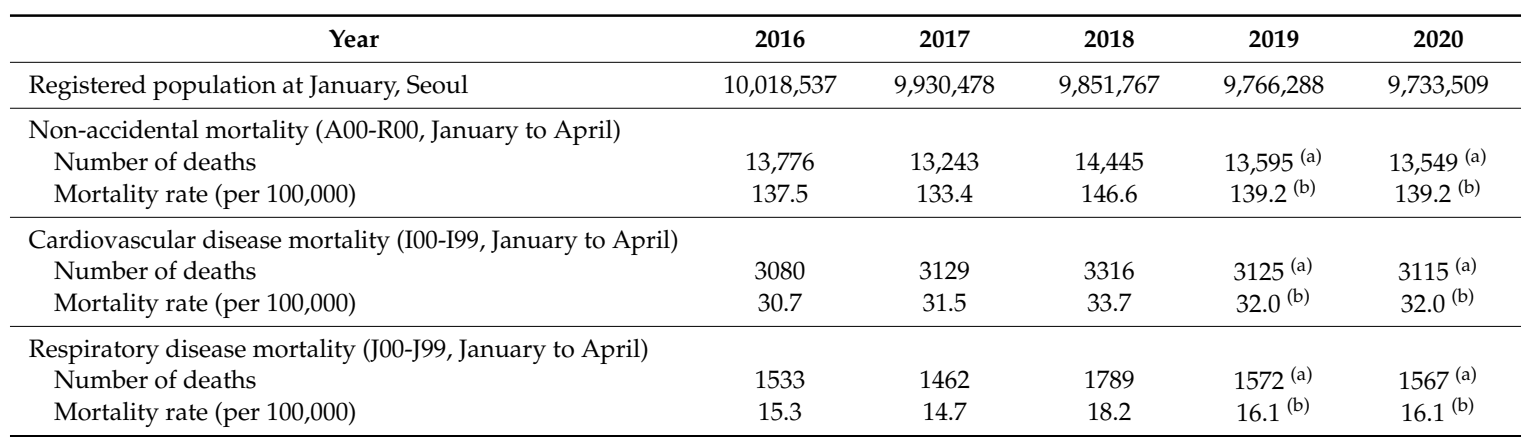

${ }^{(a)}$ Calculated based on the estimated mortality rate, ${ }^{(b)}$ Estimated by averaging year 2016-2018 mortality rate. 
Figure 2, Table S2, and Figure S2 show the number of mortalities attributable to $\mathrm{PM}_{2.5}$ exposure in Seoul from January to April each year from 2016 to 2020. By using the MCC study's RRs, the daily exposure to $\mathrm{PM}_{2.5}$ in 2020 caused 211.4 (95\% CI: 183.7, 239.0); 39.4 (95\% CI: 32.3, 47.2); and 26.6 (95\% CI: $19.1,34.0)$ deaths due to non-accidental, cardiovascular, and respiratory diseases, respectively (Table S2). The mortality attributable to the daily $\mathrm{PM}_{2.5}$ exposure was the lowest in 2020 compared to those of the previous 4 years (Figure 2). The results using RRs from the Seoul study are summarized in Table S2 and Figure S2.
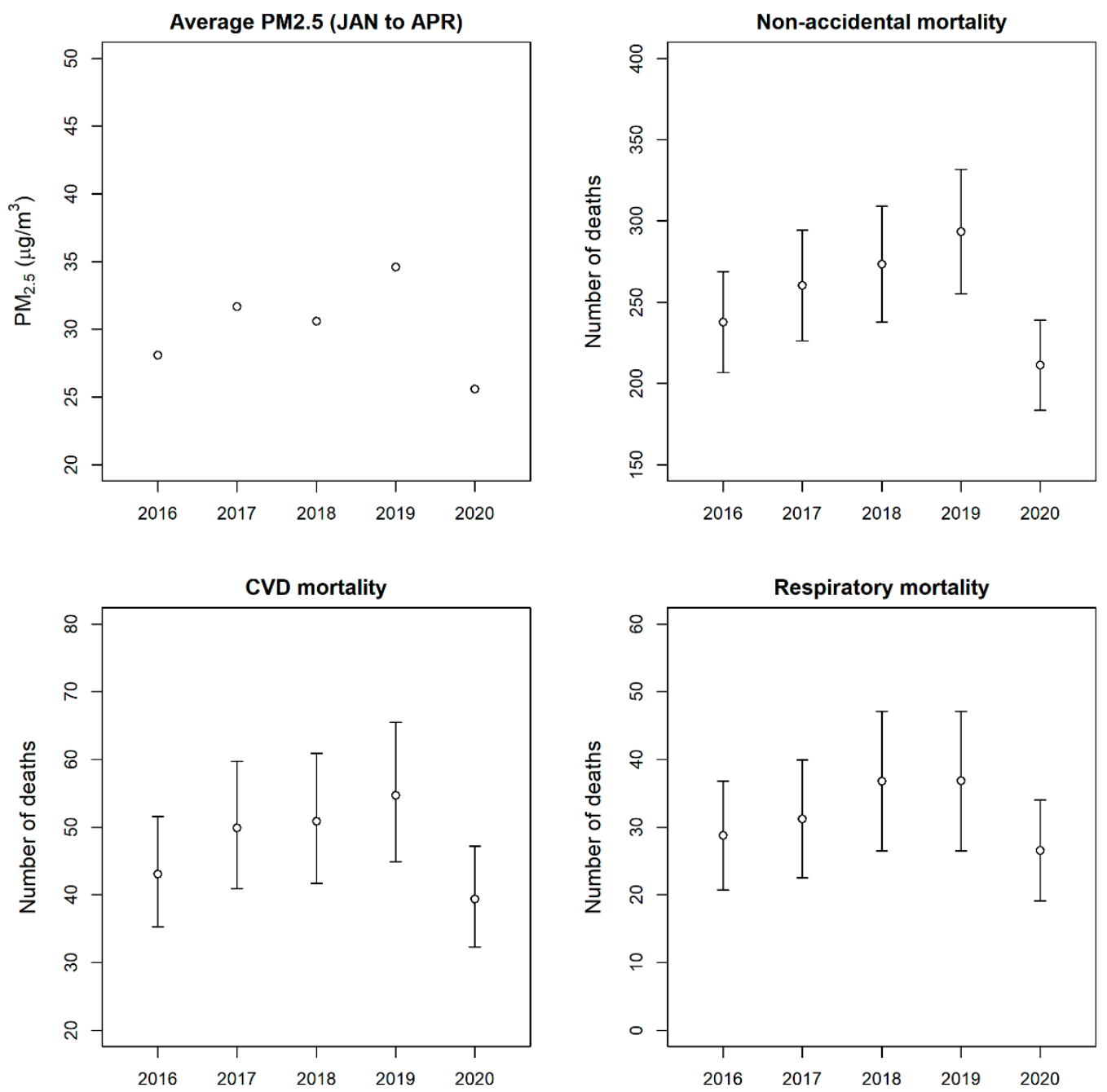

Figure 2. Average $\mathrm{PM}_{2.5}$ concentration of Seoul from January to April of 2016 to 2020 and estimated number of mortalities attributable to $\mathrm{PM}_{2.5}$ exposure (RRs from the MCC study were used for the estimation).

Table 3 shows the estimated $\mathrm{PM}_{2.5}$ reduction levels and the avoided mortality due to the $\mathrm{PM}_{2.5}$ exposure in 2020 compared to those from 2016-2019. By simply comparing the average values, a $-5.6 \mu \mathrm{g} / \mathrm{m}^{3}$ (95\% CI: -9.0, -2.3) change in ambient $\mathrm{PM}_{2.5}$ was observed in Seoul from January to April in 2020 compared to the same months in the previous 4 years (model 1). By adjusting for meteorological variables, a $-4.1 \mu \mathrm{g} / \mathrm{m}^{3}$ (95\% CI: -7.2, -0.9) change in ambient $\mathrm{PM}_{2.5}$ was estimated (model 2). By further adjusting for years and months, a $-15.1 \mu \mathrm{g} / \mathrm{m}^{3}$ (95\% CI: -27.1, -3.2) change in ambient $\mathrm{PM}_{2.5}$ was estimated (model 3). With the conservative estimation of a $4.1 \mu \mathrm{g} / \mathrm{m}^{3}$ decrease in $\mathrm{PM}_{2.5}$ and RRs from the MCC study, we found that 37.6 (95\% CI: 32.6, 42.5) non-accidental; 7.0 (95\% CI: $5.7,8.4)$ cardiovascular; and $4.7(95 \% \mathrm{CI}: 3.4,6.1)$ respiratory mortalities were avoided because of the reduction in $\mathrm{PM}_{2.5}$ from January to April in 2020 compared to those of the previous 4 years. 
Table 3. Estimated $\mathrm{PM}_{2.5}$ reduction levels and avoided mortality due to $\mathrm{PM}_{2.5}$ exposure in January to April of 2020 compared to same month each year from 2016 to 2019.

\begin{tabular}{|c|c|c|c|c|}
\hline & Model $1^{\text {(a) }}$ & Model $2^{(b)}$ & Model $3^{(c)}$ & Model $4^{(d)}$ \\
\hline $\begin{array}{l}\text { Reduction of } \mathrm{PM}_{2.5} \text { by comparing 2016-2019 } \\
\text { and } 2020\left(\mu \mathrm{g} / \mathrm{m}^{3}\right)\end{array}$ & $-5.6(-9.0,-2.3)$ & $-4.1(-7.2,-0.9)$ & $-15.1(-27.1,-3.2)$ & $-11.2(-14.3,-8.2)$ \\
\hline \multicolumn{5}{|l|}{ Avoided cause-specific deaths } \\
\hline \multicolumn{5}{|l|}{ Estimation using RRs from MCC study } \\
\hline Non-accidental mortality & $51.3(44.6,58.1)$ & $37.6(32.6,42.5)$ & $137.9(119.8,156)$ & $102.5(89.0,115.9)$ \\
\hline Cardiovascular disease mortality & $9.6(7.8,11.5)$ & $7(5.7,8.4)$ & $25.7(21.0,30.8)$ & $19.1(15.6,22.9)$ \\
\hline Respiratory disease mortality & $6.5(4.6,8.3)$ & $4.7(3.4,6.1)$ & $17.3(12.5,22.2)$ & $12.9(9.2,16.5)$ \\
\hline \multicolumn{5}{|l|}{ Estimation using RRs from Seoul City study } \\
\hline Non-accidental mortality & $25(0.8,49.8)$ & $18.3(0.6,36.5)$ & $67.2(2.0,133.9)$ & $49.9(1.5,99.5)$ \\
\hline Cardiovascular disease mortality & $13.2(2.1,24.3)$ & $9.7(1.5,17.8)$ & $35.4(5.6,65.2)$ & $26.3(4.2,48.5)$ \\
\hline Respiratory disease mortality & $15.3(4.8,25.8)$ & $11.2(3.5,18.9)$ & $41(12.9,68.6)$ & $30.5(9.6,51.2)$ \\
\hline
\end{tabular}

By considering the effect of the meteorological variables and the particulate respirator use during 2020 (model 4), we estimated that the personal exposure to ambient $\mathrm{PM}_{2.5}$ decreased by $-11.2 \mu \mathrm{g} / \mathrm{m}^{3}$ (95\% CI: $-14.3,-8.2)$ from January to April in 2020 compared to the previous 4 years. The corresponding health benefits were decreases of 102.5 (95\% CI: 89.0, 115.9) non-accidental; 19.1 (95\% CI: 15.6, 22.9) cardiovascular; and 12.9 (95\% CI: 9.2, 16.5) respiratory mortalities.

\section{Discussion}

We observed at least a $4.1 \mu \mathrm{g} / \mathrm{m}^{3}$ decrease in ambient $\mathrm{PM}_{2.5}$ concentration in Seoul from January to April in 2020 compared to the same months in 2016-2019. We estimated that 37 persons were saved due to the reduction in $\mathrm{PM}_{2.5}$ during the 4-month period. Because using a particulate-filtrating respirator may decrease the absolute level of $\mathrm{PM}_{2.5}$ exposure for an individual, the health benefit related to air pollution during the COVID-19 crisis may be larger than our current estimation of 37 persons.

There are several possible explanations for the decrease in $\mathrm{PM}_{2.5}$ in Seoul. First, public behavioral changes such as social distancing and reduced outdoor activities to limit COVID-19 transmission may have decreased the air pollution levels. According to the mobility data based on the map navigation application on smartphones, both walking and driving by the public were decreased in Seoul after the COVID-19 crisis (Figure S3). The daily amount of traffics entering the highways and the number of citizens using the Seoul Metropolitan Area subway from January to April in 2020 dropped by $6.1 \%$ and $28.4 \%$, respectively, compared to the same months in the period 2016-2019 (Table S3). In addition, industrial activities such as the number of operating factories may have decreased due to the limited consumer demand during COVID-19 crisis, which may have resulted in decreased domestic emissions [30].

Similar improvements in air quality were observed around the world since the COVID-19 crisis, with an estimated reduction of $9 \%, 29 \%$, and $11 \%$ of ambient $\mathrm{PM}_{2.5}, \mathrm{NO}_{2}$, and ozone levels, respectively [18]. The reductions in carbon monoxide and $\mathrm{NO}_{2}$ levels were observed after the partial lockdown (school closure, work from home, avoiding gatherings, shutting down commerce, and limiting public transportation) in the city of Rio de Janeiro and São Paulo State [16,17]. During the Movement Control Order (work from home and suspend industrial activities) to isolate the source of COVID-19 in Malaysia, up to a $58.4 \%$ decrease in $\mathrm{PM}_{2.5}$ was observed [15]. By analyzing air quality monitoring data of 22 cities in India, $43 \%$ and $18 \%$ decreases in $\mathrm{PM}_{2.5}$ and $\mathrm{NO}_{2}$ were observed during the COVID-19 crisis [31].

The air pollution levels in Seoul cannot be evaluated without considering the effects of the neighboring countries, China and North Korea. By evaluating the source contribution of $\mathrm{PM}_{2.5}$ on days with severe $\mathrm{PM}_{2.5}$ concentrations (with 24-h average $\mathrm{PM}_{2.5}$ concentration of over $100 \mu \mathrm{g} / \mathrm{m}^{3}$ ) in 
Seoul, China contributed to the $\mathrm{PM}_{2.5}$ concentrations by up to $70 \%$ while the domestic contribution was $21 \%$ [20]. In addition, around $15 \%$ of $\mathrm{PM}_{2.5}$ concentration in Seoul is affected by the emission from North Korea [32]. Among the 1638 mortalities attributable to the acute exposure to high levels of $\mathrm{PM}_{2.5}$ in Korea in 2016, at least 258 and 26 deaths were estimated to have been due to the emissions from China and North Korea, respectively [33].

Because the air quality in China improved dramatically during the COVID-19 quarantine (10 February to 14 April 2020) [12-14,34], and considering the fact that China's contribution to Seoul's $\mathrm{PM}_{2.5}$ concentration is generally greater in the spring and winter [33], the decrease in $\mathrm{PM}_{2.5}$ observed in Seoul from January to April 2020 may partially be explained by the effects of China's rigorous quarantine measures and decreased industrial activities during the COVID-19 crisis. If the observed decrease in $\mathrm{PM}_{2.5}$ levels in Seoul in 2020 is indeed due to the changes related to domestic responses as well as China's response against COVID-19, the estimated mortality benefit from the lowered $\mathrm{PM}_{2.5}$ levels (37 persons) outweighs the number of the direct casualties from COVID-19 in Seoul (2 persons till 30 April 2020). Similar paradoxical phenomena, and a massive decrease in air-pollution-related mortalities and morbidities during the COVID-19 crisis are expected worldwide [14].

Another plausible explanation for the decrease in $\mathrm{PM}_{2.5}$ concentration in Seoul in 2020 is the governmental effort to reduce the domestic sources of $\mathrm{PM}_{2.5}$ [19]. With consultations with relevant ministries, a comprehensive set of measures to control the particulate matter in 2020 to 2024 was finalized on 1 November 2019 [35]. One of the measures is the seasonal management of the domestic sources of $\mathrm{PM}_{2.5}$ from December to April, when $\mathrm{PM}_{2.5}$ levels are usually high [36]. Efforts to reduce the domestic emission of $\mathrm{PM}_{2.5}$ include the shutting down of the coal-fired power plants, voluntary reduction in emissions from business sites, nationwide surveillance of emission sources, designation of low-sailing zones, and transition to low sulfur fuels for ocean vessels. In addition to these comprehensive measures, an increase in rainfall and the number of days with high wind velocity may also help to explain the decrease in $\mathrm{PM}_{2.5}$ observed in Seoul from January to March 2020 [19]. However, the relative humidity and wind speed in 2020 were similar to those of 2016 and 2017; limiting the effects of meteorological factors on $\mathrm{PM}_{2.5}$ reduction.

We may not be able to distinguish the effects of diverse governmental measures from those of domestic and international changes related to COVID-19 on the reduced $\mathrm{PM}_{2.5}$ levels in Seoul. However, it is reasonable to assume that the domestic measures (social distancing and avoidance of outside activities in Korea) and international effects (decreased $\mathrm{PM}_{2.5}$ levels during the quarantine in China) related to COVID-19 may have played a significant role at the same time. We may be able to confirm the effects of COVID-19 by observing the air pollution levels after the COVID-19 measures are lifted and by evaluating whether the effects (decrease in air pollution) cease after the treatment (measures against COVID-19) ends [37].

Although not formally published as a journal article, several reports posted on medRxiv are showing the health benefits of reduced $\mathrm{PM}_{2.5}$ levels after the COVID-19 crisis. One report estimated that the $\mathrm{PM}_{2.5}$ and $\mathrm{NO}_{2}$ levels dropped by 18.9 and $12.9 \mu \mathrm{g} / \mathrm{m}^{3}$ in China during the COVID-19 quarantine period, which led to a decrease of $3214 \mathrm{PM}_{2.5}$-related deaths and a decrease of $8911 \mathrm{NO}_{2}$-related deaths [13]. By analyzing the air pollution data from over 10,000 monitoring stations around the globe, a $9 \%, 29 \%$, and $11 \%$ reduction in ambient $\mathrm{PM}_{2.5}, \mathrm{NO}_{2}$, and ozone levels was estimated during February to April 2020, just after the global lockdown in response to COVID-19 [18]. The corresponding health benefits related to the decrease in air pollution levels were 7400 deaths and 6600 pediatric asthma cases.

After the first confirmed case of COVID-19 in Korea on 20 January 2020, the panic buying of particulate filtrating respirator led to instability in supply and demand. To tackle this issue, the Korean government adopted a "5-day rotation system for respirator" to provide equal opportunity for individuals to purchase two particulate-filtering respirators (particulate respirators capable of filtering at least $80 \%$ of the $0.6 \mu \mathrm{m}$ nonoil particulates) per week. As the Korean government instructed its citizens to wear a respirator outside the house to control COVID-19, personal level of exposure to ambient $\mathrm{PM}_{2.5}$ may have decreased from wearing a particulate respirator. With the results of the 
previous intervention study, we estimated that the effects of respirator use during COVID-19 crisis decreased the personal $\mathrm{PM}_{2.5}$ exposure level by $27.4 \%$ in addition to the decrease in ambient $\mathrm{PM}_{2.5}$ levels. We estimated that this decrease led to 102 averted deaths related to $\mathrm{PM}_{2.5}$ during the 4-month period; this is higher compared to the conservative estimation of 37 lives saved with a $4.1 \mu \mathrm{g} / \mathrm{m}^{3}$ decrease in ambient $\mathrm{PM}_{2.5}$ concentration during the COVID-19 crisis estimated in our study. We believe that using a particulate filtrating respirator not only help to block the transmission of COVID-19, but also helped to limit the adverse health effects of $\mathrm{PM}_{2.5}$.

We have previously estimated that around 12,000 premature deaths were attributable to chronic $\mathrm{PM}_{2.5}$ exposure in Korea in 2015, when the annual average of $\mathrm{PM}_{2.5}$ concentration was $24.4 \mu \mathrm{g} / \mathrm{m}^{3}$ [38]. We have also estimated that 1763 deaths solely occurred in Seoul. However, our study is different from the previous study in terms of the fact that it addressed the acute effects of $\mathrm{PM}_{2.5}$ exposure by using the RRs from previous time-series studies. With the yearly mortality information and $\mathrm{PM}_{2.5}$ measurement data for the entire year, we may be able to estimate the chronic $\mathrm{PM}_{2.5}$ exposure burden for 2020 and compare the difference with previous years. If reduced $\mathrm{PM}_{2.5}$ levels are maintained throughout 2020, we may be able to see a marked decrease in $\mathrm{PM}_{2.5}$-related burden.

Several limitations should be noted for this study. First, we adopted the RRs from previous time-series studies and ignored the possibility that the association between $\mathrm{PM}_{2.5}$ and health outcomes may have changed during the COVID-19 crisis. The Korean government instructed its citizens to avoid outdoor activities or crowded areas, and to use a respirator outside the house. Due to social distancing and the use of a respirator, the beta coefficient of exposure-response relationship may have changed. If the daily mortality data become available in the future, we may be able to confirm the changes in beta coefficient by comparing the estimates from the time-series analyses before and during the COVID-19 crisis. In addition, although we tried to adjust for the effects of respirator by using the results from previous intervention study, we also assumed that the entire public were using the particulate respirator during the COVID-19 crisis, which is unlikely. Second, we ignored the daily lag effect of $\mathrm{PM}_{2.5}$. Because mortality data are not disclosed simultaneously, we were unable to conduct a day-to-day analysis accounting for the lag effects of $\mathrm{PM}_{2.5}$. With the full mortality data of 2020, a more precise estimation can be conducted by using the daily data rather than using the 4-month (January to April) data as a whole.

Due to insufficient data and assumptions used in our study, our study estimates may be biased. Assumptions regarding mortality rates and concentration-response functions have to be validated with a daily number of mortality data and $\mathrm{PM}_{2.5}$ monitoring data in the future. However, based on the currently available data, our study may offer a glimpse into the acute health benefits of $\mathrm{PM}_{2.5}$ reduction and changes in public behaviors, which are the tangible changes experienced by the citizens in their daily lives during the COVID-19 crisis.

\section{Conclusions}

We observed at least $4.1 \mu \mathrm{g} / \mathrm{m}^{3}$ decrease in ambient $\mathrm{PM}_{2.5}$ in Seoul from January to April 2020, and this decrease is believed to be the results of the changes related to COVID-19 crisis. With our conservative estimation, a total of 37 lives were saved due to the $\mathrm{PM}_{2.5}$ reduction in Seoul from January to April 2020 compared to the same period in previous years. However, the health benefits related to the decrease in $\mathrm{PM}_{2.5}$ may be greater because of the popular use of the particulate respirator by the public during the COVID-19 crisis in Korea. We may need to verify our study findings by observing the $\mathrm{PM}_{2.5}$ levels after the COVID-19 crisis and conducting studies with a full set of daily mortality data.

Supplementary Materials: The following are available online at http://www.mdpi.com/1660-4601/17/15/5279/s1, Table S1: Concentration-response functions used in the study; Table S2: Estimated number of mortalities attributable to $\mathrm{PM}_{2.5}$ exposure from January to April in each year from 2016 to 2020; Table S3: The daily average amount of vehicles entering the Seoul Metropolitan Area highways and number of citizens who used subways of Seoul Metropolitan area from January to April each year from 2016 to 2020; Figure S1: Locations of 25 PM $_{2.5}$ monitoring stations (red circle) and meteorological station (blue circle) covering Seoul; Figure S2: Average $\mathrm{PM}_{2.5}$ concentration of Seoul from January to April and estimated number of mortalities attributable to $\mathrm{PM}_{2.5}$ exposure 
(RRs from the Seoul study were used for the estimation); Figure S3: Mobility trends of Seoul City (Mobility on 13 January 2020 was regarded as 100\%; Data was gathered from the Apple Maps Mobility Trends Reports: https://www.apple.com/covid19/mobility/).

Author Contributions: Conceptualization, C.H.; Data curation, C.H.; Formal analysis, C.H.; Funding acquisition, C.H.; Investigation, C.H.; Resources, C.H.; Software, C.H.; Supervision, Y.-C.H.; Writing-original draft, C.H.; Writing-review and editing, C.H. and Y.-C.H. All authors have read and agreed to the published version of the manuscript.

Funding: This research was supported by the research fund of Chungnam National University (2020-0892-01).

Conflicts of Interest: The authors declare no conflict of interest.

\section{References}

1. Guan, W.; Ni, Z.; Hu, Y.; Liang, W.; Ou, C.; He, J.; Liu, L.; Shan, H.; Lei, C.; Hui, D.S.C.; et al. Clinical Characteristics of Coronavirus Disease 2019 in China. N. Engl. J. Med. 2020, 382, 1708-1720. [CrossRef]

2. Huang, C.; Wang, Y.; Li, X.; Ren, L.; Zhao, J.; Hu, Y.; Zhang, L.; Fan, G.; Xu, J.; Gu, X. Clinical features of patients infected with 2019 novel coronavirus in Wuhan, China. Lancet 2020, 395, 497-506. [CrossRef]

3. Gandhi, R.T.; Lynch, J.B.; del Rio, C. Mild or Moderate Covid-19. N. Engl. J. Med. 2020. [CrossRef]

4. Wu, Z.; McGoogan, J.M. Characteristics of and important lessons from the coronavirus disease 2019 (COVID-19) outbreak in China: Summary of a report of 72314 cases from the Chinese Center for Disease Control and Prevention. JAMA 2020, 323, 1239-1242. [CrossRef] [PubMed]

5. Xie, M.; Chen, Q. Insight into 2019 novel coronavirus-An updated intrim review and lessons from SARS-CoV and MERS-CoV. Int. J. Infect. Dis. 2020, 94, 119-124. [CrossRef] [PubMed]

6. Alimohamadi, Y.; Taghdir, M.; Sepandi, M. The Estimate of the Basic Reproduction Number for Novel Coronavirus disease (COVID-19): A Systematic Review and Meta-Analysis. Korean J. Prev. Med. 2020, 53. [CrossRef] [PubMed]

7. Liu, Y.; Gayle, A.A.; Wilder-Smith, A.; Rocklöv, J. The reproductive number of COVID-19 is higher compared to SARS coronavirus. J. travel Med. 2020, 27, 2. [CrossRef]

8. The Government of the Republic of Korea. Tackling COVID-19: Health, Quarantine and Economic Measures: Korean Experience. Available online: https://ecck.eu/wp-content/uploads/2020/03/Tackling-COVID-19Health-Quarantine-and-Economic-Measures-of-South-Korea.pdf (accessed on 22 April 2020).

9. The Government of the Republic of Korea. Flattening the Curve on COVID-19, How Korea Responded to a Pandemic Using ICT. Available online: http://www.undp.org/content/seoul_policy_center/en/home/ presscenter/articles/2019/flattening-the-curve-on-covid-19.html (accessed on 22 April 2020).

10. Saadat, S.; Rawtani, D.; Hussain, C.M. Environmental perspective of COVID-19. Sci. Total Environ. 2020, 728, 138870. [CrossRef]

11. Muhammad, S.; Long, X.; Salman, M. COVID-19 pandemic and environmental pollution: A blessing in disguise? Sci. Total Environ. 2020, 728, 138820. [CrossRef]

12. Wang, P.; Chen, K.; Zhu, S.; Wang, P.; Zhang, H. Severe air pollution events not avoided by reduced anthropogenic activities during COVID-19 outbreak. Resour. Conserv. Recycl. 2020, 158, 104814. [CrossRef]

13. Chen, K.; Wang, M.; Huang, C.; Kinney, P.L.; Paul, A.T. Air Pollution Reduction and Mortality Benefit during the COVID-19 Outbreak in China. medRxiv 2020. [CrossRef]

14. Dutheil, F.; Baker, J.S.; Navel, V. COVID-19 as a factor influencing air pollution? Environ. Pollut. (Barking, Essex: 1987) 2020, 263, 114466. [CrossRef]

15. Abdullah, S.; Mansor, A.A.; Napi, N.N.L.M.; Mansor, W.N.W.; Ahmed, A.N.; Ismail, M.; Ramly, Z.T.A. Air quality status during 2020 Malaysia Movement Control Order (MCO) due to 2019 novel coronavirus (2019-nCoV) pandemic. Sci. Total Environ. 2020, 729, 139022. [CrossRef] [PubMed]

16. Dantas, G.; Siciliano, B.; França, B.B.; da Silva, C.M.; Arbilla, G. The impact of COVID-19 partial lockdown on the air quality of the city of Rio de Janeiro, Brazil. Sci. Total Environ. 2020, 729, 139085. [CrossRef] [PubMed]

17. Nakada, L.Y.K.; Urban, R.C. COVID-19 pandemic: Impacts on the air quality during the partial lockdown in São Paulo state, Brazil. Sci. Total Environ. 2020, 730, 139087. [CrossRef] [PubMed]

18. Venter, Z.S.; Aunan, K.; Chowdhury, S.; Lelieveld, J. COVID-19 lockdowns cause global air pollution declines with implications for public health risk. medRxiv 2020. [CrossRef] 
19. Korea Ministry of Environment (KMOE). Results from Introduction of the Fine Dust Seasonal Management System in December 2019 Joint-Report (in Korean). 2020. Available online: https://www.gov.kr/portal/ ntnadmNews/2131027 (accessed on 22 April 2020).

20. Kim, B.-U.; Bae, C.; Kim, H.C.; Kim, E.; Kim, S. Spatially and chemically resolved source apportionment analysis: Case study of high particulate matter event. Atmos. Environ. 2017, 162, 55-70. [CrossRef]

21. Lim, Y.-H.; Kim, W.; Choi, Y.; Kim, H.-C.; Na, G.; Kim, H.-R.; Hong, Y.-C. Effects of Particulate Respirator Use on Cardiopulmonary Function in Elderly Women: A Quasi-Experimental Study. J. Korean Med. Sci. 2020, 35, e64. [CrossRef]

22. Liu, M.; Huang, Y.; Ma, Z.; Jin, Z.; Liu, X.; Wang, H.; Liu, Y.; Wang, J.; Jantunen, M.; Bi, J. Spatial and temporal trends in the mortality burden of air pollution in China: 2004-2012. Environ. Int. 2017, 98, 75-81. [CrossRef]

23. Liu, C.; Chen, R.; Sera, F.; Vicedo-Cabrera, A.M.; Guo, Y.; Tong, S.; Coelho, M.S.; Saldiva, P.H.; Lavigne, E.; Matus, P. Ambient particulate air pollution and daily mortality in 652 cities. N. Engl. J. Med. 2019, 381, 705-715. [CrossRef]

24. Kim, T.-Y.; Kim, H.; Yi, S.-M.; Cheong, J.-P.; Heo, J. Short-term effects of ambient PM2. 5 and PM2. 5-10 on mortality in major cities of Korea. Aerosol Air Qual. Res. 2018, 18, 1853-1862. [CrossRef]

25. Bhaskaran, K.; Gasparrini, A.; Hajat, S.; Smeeth, L.; Armstrong, B. Time series regression studies in environmental epidemiology. Int. J. Epidemiol. 2013, 42, 1187-1195. [CrossRef] [PubMed]

26. Statistics Korea. MicroData Integrated Service Website. Available online: https://mdis.kostat.go.kr/extract/ extSimpleSurvSearch.do?curMenuNo=UI_POR_P1200 (accessed on 22 April 2020).

27. Statistics Korea. Statistical Database Website. Available online: http://kosis.kr/statisticsList/statisticsList_ 01List.jsp?vwcd=MT_ZTITLE\&parentId=A\#SubCont (accessed on 22 April 2020).

28. Korea Environment Corporation. Air Korea Website. Available online: https://www.airkorea.or.kr/web (accessed on 22 April 2020).

29. Cohen, A.J.; Brauer, M.; Burnett, R.; Anderson, H.R.; Frostad, J.; Estep, K.; Balakrishnan, K.; Brunekreef, B.; Dandona, L.; Dandona, R. Estimates and 25-year trends of the global burden of disease attributable to ambient air pollution: An analysis of data from the Global Burden of Diseases Study 2015. Lancet 2017, 389, 1907-1918. [CrossRef]

30. Chakraborty, I.; Maity, P. COVID-19 outbreak: Migration, effects on society, global environment and prevention. Sci. Total Environ. 2020, 728, 138882. [CrossRef]

31. Sharma, S.; Zhang, M.; Gao, J.; Zhang, H.; Kota, S.H. Effect of restricted emissions during COVID-19 on air quality in India. Sci. Total Environ. 2020, 728, 138878. [CrossRef]

32. Bae, M.; Kim, H.C.; Kim, B.-U.; Kim, S. PM 2.5 Simulations for the Seoul Metropolitan Area:(V) Estimation of North Korean Emission Contribution. J. Korean Soc. Atmos. Environ. 2018, 34, 294-305. [CrossRef]

33. Lim, Y.-H.; Kim, S.; Han, C.; Bae, H.-J.; Seo, S.-C.; Hong, Y.-C. Source country-specific burden on health due to high concentrations of PM2. 5. Environ. Res. 2020, 182, 109085. [CrossRef]

34. Wang, Q.; Su, M. A preliminary assessment of the impact of COVID-19 on environment-A case study of China. Sci. Total Environ. 2020, 728, 138915. [CrossRef]

35. Korea Ministry of Environment (KMOE). Comprehensive Measures for Fine Particulate Matter (2020-2024). Available online: http://www.me.go.kr/home/web/policy_data/read.do?menuId=10262\&seq= 7399 (accessed on 22 April 2020).

36. Korea Ministry of Environment (KMOE). Special Measures for High Concentration Fine Particulate Matter Period (December 2019 to March 2020) (in Korean). Available online: http://www.me.go.kr/home/web/ policy_data/read.do?menuId=10262\&seq=7399 (accessed on 22 April 2020).

37. Shadish, W.R.; Cook, T.D.; Campbell, D.T. Experimental and Quasi-Experimental Designs for Generalized Causal Inference; William, R.S., Thomas, D.C., Donald, T.C., Eds.; Houghton Mifflin: Boston, MA, USA, 2002.

38. Han, C.; Kim, S.; Lim, Y.-H.; Bae, H.-J.; Hong, Y.-C. Spatial and temporal trends of number of deaths attributable to ambient PM2. 5 in the Korea. J. Korean Med. Sci. 2018, 33, e193. [CrossRef]

(C) 2020 by the authors. Licensee MDPI, Basel, Switzerland. This article is an open access article distributed under the terms and conditions of the Creative Commons Attribution (CC BY) license (http://creativecommons.org/licenses/by/4.0/). 